ASE-19-0005

Descriptive Article

\title{
A Look at the Anatomy Educator Job Market: Anatomists Remain in Short Supply
}

\author{
Adam B. Wilson, ${ }^{1}$ Andrew J. Notebaert, ${ }^{2}$ Audra F. Schaefer, ${ }^{2,3}$ Bernard J. Moxham, ${ }^{4}$ Shiby \\ Stephens, ${ }^{4}$ Caroline Mueller, ${ }^{2}$ Michelle D. Lazarus, ${ }^{5}$ Aaron Z. Katrikh, ${ }^{6}$ William S. \\ Brooks $^{7, *}$
}

${ }^{1}$ Department of Cell and Molecular Medicine, Rush University, Chicago, Illinois

${ }^{2}$ Department of Neurobiology and Anatomical Sciences, University of Mississippi Medical

Center, Jackson, Mississippi

${ }^{3}$ Department of Biology, College of Liberal Arts, The University of Mississippi, Oxford,

Mississippi

${ }^{4}$ School of Biosciences, Cardiff University, Cardiff, Wales, United Kingdom

${ }^{5}$ Monash Centre for Human Anatomy Education and Monash Centre for Scholarship in Health

Education, Department of Anatomy and Developmental Biology, Monash University, Clayton,

Victoria, Australia

${ }^{6}$ Rush Medical College, Rush University, Chicago, Illinois

${ }^{7}$ Department of Cell, Developmental, and Integrative Biology, University of Alabama at Birmingham, School of Medicine, Birmingham, Alabama 
Running Title: Anatomists remain in short supply

*Correspondence to: Dr. William S. Brooks, Department of Cell, Developmental, and Integrative Biology, University of Alabama at Birmingham, Volker Hall 228, $17202^{\text {nd }}$ Ave. S., Birmingham, AL 35294. USA. E-mail: wbrooks@uab.edu 


\section{ABSTRACT}

In 2002, a widely publicized report projected an anatomy educator shortage based on department chairpersons' perceptions. Now, 17 years later, the question lingers: “Does an anatomy educator shortage persist and, if so, how severe is the shortage?" Trends in the number, type, and fill rate of anatomy educator job openings were explored by analyzing United States (U.S.) job postings over the past two years. A survey was distributed to leaders of anatomyrelated departments in the U.S., Canada, and European Union. Most departmental leaders who responded $(65 \%$ or more $)$ from the U.S./Canada $(n=81)$ and the European Union $(n=52)$ anticipate they will have 'moderate' to 'great' difficulty hiring anatomy educators in gross anatomy, histology, and embryology over the next five years. Within the U.S., the number of anatomy educator job postings at medical schools more than doubled from at least 21 postings in 2017 to 52 postings in 2018. Twenty-one percent of postings between 2017 and 2018 were never filled. While the number of anatomy educator openings within the U.S./Canada is perceived to remain in a steady state for the next five years, the European Union estimates a five-fold increase in the number of openings. Departmental leaders prioritize anatomy educator applicants who have teaching experience (mean $=4.64$ on 5 -point scale), versatility in teaching multiple anatomy disciplines (mean $=3.93$ ), and flexibility in implementing various teaching pedagogies (mean $=3.69)$. Collectively, these data suggest the shortage of anatomy educators continues in the U.S./Canada and the European Union.

Key Words: anatomical sciences education, job market, anatomy faculty 


\section{INTRODUCTION}

For more than 50 years, perceived shortages of educators in the anatomical sciences have been reported. In the early 1960's, Eldred and Eldred (1961) cited a “chronic insufficiency of personnel and teaching positions" in anatomy, noting a large number of unfilled faculty positions in United States (U.S.) anatomy departments which was coupled with a decrease in the number of doctoral degrees awarded in anatomy. A decade later, Blevins and Cahill (1973) published a study based upon perceptions of chairpersons of anatomy departments in U.S. and Canadian medical schools, which indicated a persistence of the problem. That same decade, a letter to the editor published in Medical Education indicated that the shortage of anatomists extended into Europe as well (Bird, 1979). Fast forward 23 years to 2003 when two popular publications printed in Science and the AAMC Reporter warned of an impending shortage of qualified anatomy instructors at health profession institutions (AAAS, 2003; Santana, 2003). These projections were based on a 2002 national survey jointly sponsored by the American Association of Anatomists (AAA) and the Association of Anatomy, Cell Biology, and Neurobiology Chairpersons (AACBNC), which reported that "more than $80 \%$ of the chairs of departments responsible for teaching anatomy anticipated having 'moderate' to 'great' difficulty recruiting qualified faculty to teach gross anatomy" (McCuskey et al., 2005). In the decade and a half since the findings of this most recent survey, it remains unclear whether this perceived shortage continues to persist across the U.S./Canada and European countries. Some contend that the longterm consequences of this shortage and the subsequent deficit of expert anatomical knowledge may have far-reaching, chain reaction-like implications including an adverse impact on patient safety (Older, 2004; Waterston and Stewart, 2005; Ahmed et al., 2010; Yammine, 2014). 


\section{Contributing Factors and Changing Medical Education Landscape}

The prevailing factors responsible for the shortage of anatomy educators are multifaceted and interdependent. Ph.D. graduate programs in the latter part of the $20^{\text {th }}$ century began emphasizing molecular and cellular biology research (Moosman, 1980). Indeed, many graduate programs removed gross anatomy experiences from their training requirements entirely (Malamed and Seiden, 1995; McCuskey et al., 2005). This caused a sharp shift in the training paradigm of graduate biomedical programs, which transitioned from producing general anatomists to cultivating researchers with specialty concentrations (Rizzolo and Drake, 2008; Brokaw and O'Loughlin, 2015). In fact, a recent study by Schaefer et al. (2019) reported that $16 \%$ of graduate-level educators in the anatomical sciences lack graduate coursework in gross anatomy and almost 40\% lack similar coursework in embryology, histology, and neuroanatomy. By refocusing the training of next generation academics, a dearth of educators formally trained in the teaching of the anatomical sciences became an unintended consequence.

More recently, academic health institutions have undergone organizational restructurings in the wake of economic hardships. For instance, the economic downturn within the U.S. in the 2000's resulted in reduced funding from the National Institutes of Health and increased pressure on faculty to seek out competitive grants to support, and sometime fully-fund, their own salaries (Alberts et al., 2014; Stimpson et al., 2014). The balance between hiring talented educatorscholar faculty is thought to have shifted toward hiring a greater number of well-funded research-focused faculty within anatomy-related departments (Moosman, 1980).

Reductions in the number of contact hours allotted to the anatomical sciences (Drake et al., 2002, 2009, 2014; McBride and Drake, 2018) and the modernization of medical school curricula are contextually important changes that coincide with a decline of anatomy educators. 
Presently, the average time allocated to gross anatomy in U.S. medical school curricula is 129 hours (McBride and Drake, 2018). In Europe, an average of 120 hours and 90 hours of anatomy instruction (excluding neuroanatomy) are reported for French and United Kingdom (U.K.) medical schools, respectively (Plaisant et al., 2004; Gogalniceanu et al., 2009). From a curricular perspective, anatomical sciences instruction within most U.S. medical schools has been absorbed into highly integrated system-based courses (McBride and Drake, 2018), many of which incorporate active learning approaches and more clinically focused topics (Sugand et al, 2010; Drake and Pawlina, 2014; Lufler et al., 2010; Ahmed et al., 2011; Orsbon et al., 2013). Similarly, biomedical science infrastructures have also broadly subscribed to integration whereby many university departments have coalesced and rebranded themselves to assert their research focus. As such, anatomists and the anatomy profession at large may have lost a piece of their professional identity when traditional 'Departments of Anatomy' integrated with other basic science departments (e.g., Cell Biology, Neuroscience, or Biological Sciences); which rarely showcase the anatomy discipline in their titles. These contributing factors in combination with profession-related changes may explain why reaching homeostasis between the supply and demand for anatomy educators continues to be a challenge.

\section{Attempts to Reverse the Anatomy Educator Shortage}

Historically, in an attempt to compensate for workforce shortages in higher education, institutions have called upon adjunct faculty and/or sessional teachers (e.g., more senior graduate/medical students or master's trained individuals) to fill lingering educator gaps (Caruth and Caruth, 2013; Lachman et al., 2013; Rhodes et al., 2018). To more permanently remedy a deficit of classically trained anatomy educators, a handful of graduate, postdoctoral, certificate, 
and continuing education/professional development programs specific to the anatomical sciences have been developed. For example, some U.S. institutions (e.g., Indiana University and the University of Mississippi Medical Center) offer Ph.D. training programs focused solely on education in the anatomical sciences (Brokaw and O'Loughlin, 2015). Other U.S. programs (e.g., Boston University and the University of Kentucky) provide opportunities for graduate students to hone their teaching skills through training and apprenticeships (Richardson-Hatcher et al., 2018); Boston University, 2019). For a comprehensive listing of traditional anatomy-related training programs refer to the American Association of Anatomists website (AAA, 2019a) which currently lists 53 institutions with graduate programs. Concerning continuing education (CE), a recent survey of anatomy educators in the U.S. demonstrated that $81 \%$ of respondents felt a need for CE programs in the anatomical sciences as anatomists generally value learning about educational methodologies and pedagogies. However, the availability of both CE programs and postdoctoral fellowships in anatomy education are rare (Wilson et al., 2018; Schaefer et al., 2019).

Outside of the U.S., very little is known about the current status of anatomy educator positions. In the U.K. and Ireland, curricular changes and the dwindling popularity of anatomy have been perceived as the cause for a decline in the number of new anatomy educators (Fraher and Evans, 2009). This has likely been exacerbated by research assessment exercises in the U.K. where league tables for universities and medical schools are based entirely on research output. Shortages of anatomists in Europe may be a factor in the perception among European institutions that there is a decline in the esteem for anatomy in the medical curriculum, despite robust evidence that both medical students and the lay-public regard anatomy as being highly clinically relevant (Moxham and Moxham, 2007; Moxham and Plaisant, 2007; Patel and Moxham, 2008; 
Kerby et al., 2011; Plaisant et al., 2014). To combat the perceived shortage, the Anatomical Society in the U.K., in partnership with the AAA, has committed to fostering the training of the next generation of anatomists by establishing an Anatomy Training Program which provides certificates in anatomy teaching to aid faculty in their transition to anatomy teaching roles (Fraher and Evans, 2009).

\section{Does a shortage still remain?}

As various graduate and postdoctoral training programs make a deliberate effort to trainup additional anatomy educators worldwide, justifying the missions of these programs requires that an ongoing research effort be made to quantitatively monitor the anatomy educator job market, including employers' needs and preferences. The most recent study surveying the anatomy educator workforce was limited to the U.S. and Canada, and the data from that study are now 17 years old (McCuskey et al., 2005). Therefore, the principal aim of this study was to determine the extent to which an anatomy educator shortage currently exists within U.S./Canadian and European Union institutions responsible for training health professionals. Additionally, this study sought to discern which training and experience characteristics departmental leaders prioritize when reviewing and/or interviewing prospective candidates for anatomy educator positions. 


\section{METHODS}

\section{Analysis of Anatomy Educator Job Postings}

In order to contextualize the actual need for anatomy educators, job vacancy notices posted to the AAA job board (AAA, 2019b) in 2017 and 2018 were obtained from the American Association of Anatomists. The total number of job postings was used for trend analysis.

Administrative leaders from each U.S./Canadian department, school, or college that posted a job advertisement were invited by email to participate in the Survey of Anatomy Educator Job Postings (Supplementary Material Appendix A), which investigated the hiring experiences of departments seeking anatomy educators over the two calendar years.

The characteristics of anatomical sciences educator job postings for U.S. medical schools in 2017 and 2018 were collected from three different websites, including the AAA job board (AAA, 2019b), the American Association of Clinical Anatomists (AACA) Job Openings site (AACA, 2019), and a higher education job aggregator website (HigherEdJobs, 2019). Postings were assessed through document analysis. Data collection began with an initial review of current openings on the AAA and AACA websites. For the higheredjobs.com site, the key words "Anatomy" and "Teach" were used as an initial filter. For the AAA and higheredjobs.com websites, a 'job agent' was created which automatically forwarded notifications of all new listings. The AACA website was reviewed approximately every two months for new listings. All listings were reviewed independently by two researchers to assess eligibility criteria. To be eligible for analysis, listings had to reference open anatomy educator positions at a U.S. medical school/center. Duplicated listings were noted, and only the earliest posting of the position was used for analysis. For each position notice, the following data were collected: name and location of the institution, institutional type (e.g., osteopathic versus allopathic), offered rank (i.e., 
instructor, assistant, associate, or full professor), and whether the position was designated as tenure or non-tenure track. Minimum academic qualifications and position requirements beyond the scope of teaching, such as research funding and/or scholarship expectations, were also noted. Analysis of these data was restricted to frequency counts.

\section{Departmental Leadership Survey}

The Survey of Anatomy-Related Department Leadership (Supplementary Material Appendix B) explored the composition of academic departments that house faculty responsible for anatomical sciences instruction, assessed the perceived need for anatomy educators, and identified the desired characteristics and training experiences of anatomy educator job applicants. This survey was distributed to a broad audience of search committee members and department administrators in the U.S./Canada and European Union through multisource distribution mechanisms including the Anatomy Connected message board of the AAA, member list-serves (i.e., the AACBNC, the Anatomical Society in the U.K. and Ireland, and the Trans-European Pedagogic Anatomical Research Group of the European Federation for Experimental Morphology), and Twitter® (Marsland and Lazarus, 2018). Survey instructions specified that those completing the survey must be either departmental leaders (e.g., chair or vice chair) or must have served on a faculty search committee within the past five years. Survey responses from individuals outside of the U.S./Canada, and European Union were excluded from the analyses $(n=26)$. Survey response rates could not be accurately computed due to multisource distribution (e.g., message boards, society list-serves, email, Twitter ${ }^{\circledR}$ ), which precluded an accounting of the total population of departmental leaders. The survey was piloted using a 
convenience sample of departmental leaders and subsequently edited for item clarity and specificity based on feedback prior to distribution in its final form.

\section{Data Analysis}

Survey data were collected through Qualtrics XM (Qualtrics, Provo, UT) and were exported to SPSS statistical package, version 22 (IBM Corp., Armonk, NY) for further organization, cleaning, and analysis. Descriptive statistics in the form of frequencies were used to calculate response rates and to quantify respondents' perceptions. The reliability of scaled perceptions items was assessed using Cronbach's alpha. A one-way MANOVA investigated differences in perceived recruitment difficulty between the U.S./Canada and the European Union across five anatomy disciplines. The study protocol for this research project received exempt approval from the Institutional Review Board at the University of Alabama at Birmingham (Protocol IRB-300001944).

\section{RESULTS}

\section{Anatomy Educator Shortage as Determined by Job Postings}

\section{Trends and Outcomes of Posted Positions}

The number of U.S./Canadian AAA job board postings for anatomy educator positions (excluding postdoctoral and administrative positions) at all institutional types (including medical, health sciences, and undergraduate institutions) collected and analyzed for this study were 87 and 85 posting in 2017 and 2018, respectively. Between January 2017 and December 2018, 135 different institutions posted job advertisements to the AAA job board with some institutions posting multiple openings. Departmental leaders from each institution were surveyed regarding 
hiring experiences. The response rate from this survey was $37 \%$ (i.e., 50 schools with 76 unique postings out of 135 institutions total). The three most common reasons for posting jobs ads were faculty turnover (e.g., faculty moving to another institution), faculty retirement, and growth in academic programs and enrollments. From the responding departments, $69.7 \%$ of positions (53 of 76) were filled within 1 year or less. Conversely, $28.9 \%$ of positions (22 of 76) were either unfilled at the time the survey was completed or remained vacant greater than one year (Table 1). When asked to report the number of qualified applicants who applied to anatomy educator positions, nearly half (47.9\%; 34 of 71) of departments reported having three or fewer qualified applicants (Table 1). Survey respondents further indicated that the small pool of qualified applicants was the most common reason for failure to fill a position. Candidates with a terminal degree in a basic science discipline $(26 \% ; 20$ of 76$)$ or a focus in anatomical sciences education (22\%; 17 of 76$)$ were most commonly hired.

\section{Characteristics of U.S. Medical School Job Postings}

To explore job posting characteristics within a homogeneous population, only anatomy educator job postings at U.S. medical schools in 2017 and 2018 were compiled from three online sources (Table 2). Of the 73 unique job notices (having removed duplicate postings), 21 were posted in 2017 and 52 were posted in 2018, an increase of 148\%. A total of 57 different medical schools posted vacancies. Demographics for U.S. job notices are compared in Table 2.

Despite the fact that U.S. osteopathic medical schools represent only $18.4 \%$ of all U.S. medical schools (34 of 185), an equal number of postings were placed by osteopathic ( $\mathrm{n}=36)$ and allopathic $(n=37)$ medical schools, suggesting a greater need amongst institutions granting the Doctor of Osteopathic Medicine degree. Over the past two years, most anatomy educator job 
openings called for faculty at an open rank (60\%; 44 of 73) and required a Ph.D. or equivalent (92\%; 67 of 73). A demonstration of grantsmanship and research/scholarly activity were infrequently indicated as a requirement of applicants to anatomy educator positions.

\section{Anatomy Educator Shortage as Perceived by Department Leaders}

Of the 133 respondents to the Survey of Anatomy-Related Department Leadership, $60.9 \%$ of responses were from the U.S./Canada and 39.1\% from countries in the European Union. Departmental leaders of various types (i.e., department chairs, vice chairs or equivalent, search committee chairs, and search committee members) were well represented and were mostly associated with basic science departments with medical school affiliations (Supplementary Material Appendix C).

\section{Departmental Composition of Faculty}

Across all institutions represented, anatomy-related departments reported a mean of 12.7 full-time primary faculty (academic staff) with a range from 1 to 40 . Of these primary faculty, $38.6 \%$ devote greater than $50 \%$ of their work effort to anatomical sciences instruction and another $30.0 \%$ devote $10-50 \%$ of their work effort to anatomy education. Of the responding departments, $30.1 \%$ ( 40 of 133 ) rely on at least 1 part-time or adjunct faculty (mean $=4.6$; range $=1-12$ ) to fill teaching roles in anatomical sciences instruction. Most faculty who participate in instruction within gross anatomy, histology/microscopic anatomy, and embryology/developmental biology have primary responsibilities in education ( $\geq 55.6 \%$ ), while faculty who teach cell biology are primarily biomedical research-focused faculty (54.9\%; Figure 
1). Neuroanatomy/neuroscience courses are taught almost equally by both education-focused (43.6\%) and research-focused faculty (48.1\%).

\section{Anticipated Recruitment Difficulties}

The internal consistency of scaled perceptions items was 0.712 for 22 items across 3 domains. When asked to rate the anticipated difficulty of recruiting qualified individuals to teach in the anatomical sciences over the next five years, $48 \%$ or more of respondents perceived they would have 'moderate' to 'great' difficulty in recruiting educators to teach in the four classic anatomy disciplines (Figure 2). On the other hand, the majority of respondents (68\%) felt they would have 'little to no difficulty' in recruiting faculty to teach cell biology. Compared to 2002 data, fewer department leaders now anticipate 'moderate' to 'great' difficulty in recruiting gross anatomy educators ( $83 \% 2002$ vs. $65 \% 2018$ ), while minimal changes were observed concerning the recruitment of histology and neuroanatomy educators (Figure 2). Because the 2002 survey did not include embryology or cell biology, these data comparisons were not available. Responses regarding recruitment difficulty in each discipline were homogenous between the U.S./Canada and the European Union $(\mathrm{p}=0.099)$.

Over the next five years, collectively, department chairs in the U.S./Canada anticipate remaining in a steady state with little fluctuation in the number of anatomy educator openings compared to the 2018 landscape (Figure 3). Within the European Union, however, departments anticipate a five-fold increase in the number of anatomy educator openings between 2019 and 2023 (Figure 3). 


\section{Recruitment Priorities}

When recruiting candidates for full-time faculty (academic staff) positions as anatomy educators, $94.2 \%$ of departmental leaders ranked 'experience in anatomical sciences teaching' as the most sought after quality/experience in applicants. Respondents also considered 'teaching versatility across multiple anatomical disciplines' (72.1\%), one’s 'versatility in teaching methods/pedagogies' (68.0\%), and a 'peer-reviewed publication record' $(59.6 \%)$ to be of moderate to high priority in recruitment (Figure 4A). Regarding candidates' training backgrounds, leaders of anatomy-related departments who are seeking educators prioritize individuals with a Ph.D. in anatomical sciences education (67.0\%) or those with a Ph.D. in the basic sciences (e.g., cell biology, neuroscience, etcetera; 58.1\%; Figure 4B). Candidates with a clinical doctorate (e.g., MD, DPT, etcetera; 39.8\%) and those with a master's degree in anatomical sciences education (34.0\%) were favored over those with a Ph.D. in anthropology (27.2\%). Additionally, the majority of departmental leaders are most interested in recruiting individuals at the rank of assistant professor (56.4\%; 75 of 133) followed by the rank of lecturer/instructor $(32.3 \%$; 43 of 133$)$.

\section{DISCUSSION}

According to faculty departure data from the Association of American Medical Colleges (AAMC), faculty turnover rates amongst U.S. medical schools are estimated to be $8 \%$ annually (i.e., 14,224 faculty departures / 176,732 faculty in 2018; AAMC, 2019). More broadly, within higher education, the turnover rate of 124 different education administrator positions is reported to be $12 \%$ on average, with the highest turnover amongst Deans/Directors of Education at $22 \%$ (HigherEd Direct, 2019). Interestingly, the present study indicates that $21 \%$ of anatomy educator 
positions were unfilled at the time departments were queried on their 2017 and 2018 job postings. This proportion of unfilled positions (21\%) exceeds typical faculty turnover estimates (8-12\%), suggesting an anatomy educator shortage continues to persist and is not merely an artifact of typical faculty turnover. The perceptions of departmental leaders from the U.S./Canada and the European Union also supports an anatomy educator shortage as leaders anticipate having 'moderate' to 'great' difficulty in recruiting faculty to teach gross anatomy (65\%), histology (66\%), embryology (70\%), and neuroanatomy (48\%) over the next five years.

\section{What progress has been made since the last shortage report?}

Previously, McCuskey et al. (2005) provided a set of general recommendations to address the ostensible shortage of anatomy educators. The first recommendation was to reduce the individual teaching load of gross anatomy educators by making courses team-taught. The philosophy that "many hands make light work" appears not to have played out in practice. According to the present data, approximately $74 \%$ of department leaders reported gross anatomy educators have education as their primary responsibility (Figure 1), and across all faculty who teach in the anatomical sciences $38.6 \%$ do so as a substantial portion (FTE > 50\%) of their primary workload.

Another suggestion made by McCuskey and colleagues (2005) to address the anatomy educator shortage was to re-institute training grants that include support for teacher training in anatomy. Modest progress has been made on this front with the NIH-funded Institutional Research and Academic Career Development Award (IRACDA). Most notably, the former Scientist-Educator Program at Vanderbilt University (Bader et al., 2010) produced a number of anatomy educators through the IRACDA funding mechanism. The Scientist-Educator Program 
ended, though, when funding ceased due to non-renewal, underscoring the importance of funding avenues for sustained teacher training in anatomy.

\section{What does the future hold for the profession of anatomy education?}

Unless meaningful measures are taken to address the shortage of anatomical sciences educators, the problem may worsen over the next decade. The Association of American Medical Colleges (AAMC) predicts that the U.S. could face a dramatic shortage of both primary care and specialty physicians by the year 2030 (Dall et al., 2018). As such, both allopathic and osteopathic medical schools are expected to continue to increase enrollments, some of which have already seen increases approaching 30\% since 2002 (AAMC, 2018). In addition, new medical schools and new health professions programs are continually being developed in response to projected healthcare needs both within the U.S. and other nations. In fact, over five years from 2014 to 2018, 17 new U.S. medical schools were established and the number of U.S. health professions programs surged at a staggering rate (Table 3). In the U.K., five new medical schools are planned over the next three years (GMC, 2019). With increased numbers of programs dependent upon anatomy instruction and with increasing enrollments, the need for educators in the anatomical sciences is only expected to rise proportionately. Furthermore, recent years have seen professions such as physical therapy, occupational therapy, and nurse anesthesia move from entry-level master's degrees to entry-level doctoral degrees anecdotally translating to more coursework in the anatomical sciences. With these and similar professions moving to more advanced levels of training, further strain may be placed upon the anatomy educator job market to produce more anatomists qualified to teach undergraduate- and graduate-level gross anatomy to learners in a wide variety of clinical disciplines. 


\section{How might the profession work to reverse the identified shortage?}

Despite an awareness of this shortage amongst the anatomical sciences and medical education communities, only small strides have been made over the past decade and a half to overcome the shortage of qualified anatomists to teach future healthcare providers. Based on historical context and the present data, the following recommendations are proposed to 'right the ship' so that constituents of the anatomical sciences can proactively prepare for anticipated future needs.

Recommendation 1: Increase the number of training programs in the anatomical sciences

It is clear from the current study that anthropologists and clinically-trained professionals are preferred less by anatomy departmental leaders than candidates with $\mathrm{Ph} . \mathrm{Ds}$. in anatomical sciences education and the basic sciences (Figure 4B). Despite this, institutions have employed a growing number of anthropologists and non-licensed, foreign-trained physicians to combat the anatomy educator shortage (McCuskey et al., 2005). It has been reported that the number of doctoral anthropology graduates from U.S. institutions has increased by $70 \%$ over the past 30 years, yet a corresponding increase in discipline-focused jobs has not been observed (Speakman et al., 2018a; Speakman et al., 2018b). This has in turn led to a highly competitive job market for anthropologists and may explain their increased employment as anatomy educators, despite being among the least preferred candidates to fill these positions (Figure 4B). Similarly, increased immigration of international medical graduates into countries such as the U.S., Canada, and Australia, coupled with their medical training, has likely contributed to the observed 
utilization of this group as educators in the anatomical sciences (Mullan et al., 1995; Hall et al., 2004; McDonnell and Usherwood, 2008).

Higher numbers of graduates from anatomical sciences doctoral programs are warranted. However, due to the inherent challenges of funding anatomy education Ph.D. programs specifically, institutions must think creatively about the structure of their graduate programs and their financial sustainability. Two possible models for sustaining funding in the absence of grants or endowments might include: (a) incorporating a fee-for service model into the program in which graduate students are reimbursed for their teaching efforts to subsidize the cost of graduate student stipends or (b) following a tuition-based model in which graduate students pay tuition for their coursework; a practice common among higher education (e.g., EdD) and science education programs. Valuable insights for designing and managing new programs can be gained by looking to established, education-focused programs, such as Indiana University (Brokaw and O'Loughlin, 2015), or basic science Ph.D. programs with an anatomy focus, such as Pennsylvania State University (2019), as models of success. The current findings can also be used to further inform the design of new programs. For example, new programs ought to include avenues for trainees to obtain teaching experiences in multiple anatomy disciplines, experiences learning about and applying a variety of teaching methods, and mechanisms for developing a respectable publication record.

Postdoctoral programs can also contribute to the needed growth in anatomy educators. Postdoctoral fellowships have the potential to bridge graduates of basic science $\mathrm{Ph} . \mathrm{D}$. programs (e.g., cell biology, neuroscience) and perhaps doctoral programs in anthropology into anatomy education by filling gaps in their skills and experiences as educators (Schaefer et al., 2019). In conjunction with more formalized postdoctoral training in teaching the anatomical sciences, 
further progress must be made at the national level through additional NIH- and/or societyfunded training grants that offer support and require protected time for teaching, as McCuskey et al. (2005) previously suggested. Postdoctoral teaching experiences, such as those funded through the IRACDA mechanism, offer important learning opportunities for trainees who intend to pursue careers that couple bench science and education. Increasing access to these types of hybrid experiences may also help to prevent attrition of educators following postdoctoral training (McCuskey et al., 2005).

\section{Recommendation 2: Establish a profession-wide infrastructure and raise awareness}

The current lack of a profession-wide infrastructure and a scarcity of local, national, and international support for training programs may explain why the anatomy education community has been unable to keep pace with the changing and growing demands of the profession. One possible solution to help alleviate the lurking infrastructure problem is to develop a 'community of practice' among existing and budding anatomy education training programs so that valuable, yet often limited, resources (such as faculty expertise) can more easily be shared across training entities. Establishing a broad, international community of practice that fosters collaborative mentoring and that alleviates strain put on new programs may be a critical first step in preparing to fill the market's high demand for anatomy educators.

Successful development of additional anatomy education training programs must be paired with increased public awareness of the anatomy education profession. As departments of anatomy continue to be absorbed by other basic science departments, the risk of anatomists losing their professional identity grows more commonplace. In the 1990's, for example, all U.K. medical schools employed one or more Professors of Anatomy, but a cursory review of current 
university faculty indicates most $(68 \%, 23$ of 34$)$ lack individuals holding this title. The anatomy community must be able to elevate the notability of its profession so that students recognize anatomy education as a viable career path option. Public awareness campaigns such as "I am Anatomy" and outreach programs such as "Anatomy for Every Body", both sponsored by the AAA, are examples of how this issue is currently being addressed within the U.S. and Canada (AAA, 2018).

Recommendation 3: Establish regular, systematic monitoring of the anatomy educator job market and faculty pipeline.

Currently, there is no centralized annual monitoring of data related to departmental faculty composition, anatomy educator job openings, relevant postdoctoral positions, graduate student enrollments, or graduation rates. As a result, departments and training programs have no reliable means by which to benchmark their performance and needs relative to comparable programs nationally and/or internationally. If such data were collected and reported at regular intervals, like the AAMC reports for medical schools, the anatomy education community could more accurately assess needs, monitor trends, and anticipate projected shortcomings. Professional societies, such as the American Association of Anatomists (AAA), the American Association of Clinical Anatomists (AACA), or the Association of Anatomy, Cell Biology, and Neurobiology Chairpersons (AACBNC) may be well-positioned to take the lead on this type of initiative to centrally collect important programmatic, job market, and pipeline data.

\section{Study Limitations}


This study is not without limitations. First, while some countries in Europe were well represented by survey responses, representation from other countries was limited or even absent. This might suggest under-reporting in some regions, and as such, these data and predictions may not generalize to all countries within the European Union. Second, it is possible that anatomyrelated department leaders who currently have unfilled educator positions were more apt to complete surveys out of an immediate interest to compare local needs to broader findings, which may have contributed to volunteer response bias. It is also possible that despite using three independent sources to gather documented job postings at U.S. medical schools, some relevant postings may have gone undetected. Data collected regarding job postings is limited to the U.S. and Canada, and recommendations on how to remedy reported shortages may not translate to all countries due to inherent differences in professional cultures. This study focused primarily on the anatomy education job market within graduate and professional programs. As such, a lack of data regarding the job market for anatomical sciences educators within undergraduate institutions is another limitation of the study.

\section{CONCLUSIONS}

A shortage of qualified anatomical sciences educators in the U.S./Canada and the European Union persists and is likely to intensify in the coming years considering the observed increases in the number of medical and health professions programs and concomitant increases in anatomy educator job postings. The anatomy community including all of its stakeholders (i.e., anatomists, professional societies, academic medical centers, etcetera) must collaboratively and intentionally take aggressive strides towards rectifying the identified shortage and the swelling demand for educators. Steps to improve the balance between job market supply and demand 
might include 1) establishing programs and funding mechanisms to better support graduate and postdoctoral training, 2) creating an infrastructure and increasing awareness of anatomy education as a career option, and 3) more regularly monitoring job market tendencies. Because it is unclear how many budding anatomists currently exist in the pipeline, future work exploring this unknown may help the profession to better understand how current training models and outreach campaigns can be modified to become more convergent with job market needs. Finally, a longitudinal systematic analysis of job market tendencies is needed to determine whether deliberate efforts to reverse the current shortage are positively effecting the job market and the 'health' of the anatomy education profession as a whole. 


\section{ACKNOWLEDGEMENTS}

The authors thank Dr. Robert McCuskey for sharing data from the 2002 Anatomy-

Related Department Chairpersons survey for inclusion in the manuscript. The authors also thank the American Association of Anatomists for its support of this research study and Shawn Boynes for providing data regarding prior AAA job postings. 


\section{NOTES ON CONTRIBUTORS}

ADAM B. WILSON, Ph.D., is an associate professor in the Department of Cell and Molecular Medicine at Rush University, Chicago, IL. He is the Director of Anatomy Education, he teaches medical gross anatomy, and his research interests within anatomy and medical education are focused on topics related to educational measurement and evaluation.

ANDREW J. NOTEBAERT, Ph.D., is an assistant professor in the Department of Neurobiology and Anatomical Sciences at the University of Mississippi Medical Center (UMMC) in Jackson, Mississippi. He also serves as the Program Director for the Ph.D. in Clinical Anatomy at UMMC. He teaches education-based courses to graduate students and conducts research on student perceptions of learning in anatomy and in medical school.

AUDRA F. SCHAEFER, Ph.D., is an assistant professor in the Department of Neurobiology and Anatomical Sciences at the University of Mississippi Medical Center (UMMC) in Jackson, Mississippi, and an adjunct assistant professor in the Department of Biology at the University of Mississippi, Oxford, Mississippi. She teaches neuroanatomy to medical students, histology to dental students, and her research interests include self-directed learning in medical education, metacognition, and the impacts of mindset on learning.

BERNARD JOHN MOXHAM, Ph.D., is emeritus professor of Anatomy in the School of Biosciences at Cardiff University in Cardiff, Wales, U.K. He is a craniofacial biologist who also publishes extensively on the teaching of the biomedical sciences. He is the Immediate Past 
President of the International Federation of Associations of Anatomists, and has been President of the European Federation for Experimental Morphology and of the Anatomical Society. He founded the Trans-European Pedagogic Anatomical Research Group.

SHIBY STEPHENS, M.B.S.S., M.Phil., F.H.E.A., is a clinical anatomist in the School of Biosciences at Cardiff University in Cardiff, Wales, U.K. She teaches dissection-based gross anatomy and her present research interests are concerned with the linguistic skills and personalities of medical students and how these affect the learning of anatomy and performance in examinations. She is also involved with the development of core syllabuses for the anatomical sciences.

CAROLINE MUELLER, B.S., is a graduate student at the University of Mississippi Medical Center in Jackson, Mississippi. Her research interests are the demographics and rationale of whole body donation. Other interests include anatomy education job outlook and the formation of educational programs to suit the job demand.

MICHELLE D. LAZARUS, Ph.D., is an associate professor in the Centre for Human Anatomy Education and affiliate member of the Monash Centre for Scholarship in Health Education at Monash University, Melbourne, Australia. She currently serves as the Department of Anatomy and Developmental Biology Deputy Educational Committee Chair and teaches first- and secondyear undergraduate medical and graduate medical students. Her research interests are in the areas of professional identity and community engagement with anatomy. 
AARON Z. KATRIKH, M.S., is a medical student at Rush University. His research interests are in medical education and the anatomical sciences.

WILLIAM S. BROOKS, Ph.D., is an associate professor in the Department of Cell, Developmental, and Integrative Biology, School of Medicine at the University of Alabama at Birmingham, Birmingham, Alabama. He teaches gross anatomy to medical, dental, and physical therapy students and his research interests are in the training of anatomists and the evaluation of teaching pedagogies, especially team-based learning, in gross anatomy and medical education. 


\section{LITERATURE CITED}

AAA. 2018. American Association of Anatomists. Innovations Program Past Recipients. American Association of Anatomists, Bethesda, MD. URL:

https://www.anatomy.org/innovations-program-recipients.html [accessed 13 February 2019].

AAA. 2019a. American Association of Anatomists. Graduate Programs in Anatomy. American Association of Anatomists, Bethesda, MD. URL: http://www.anatomy.org/graduate-programsin-anatomy.html [accessed 26 February 2019].

AAA. 2019b. American Association of Anatomists. Job Listings. American Association of Anatomists, Bethesda, MD. URL: https://jobs.anatomy.org [accessed 26 February 2019].

AAAS. 2003. American Association for the Advancement of Science. Anatomy classes face gross shortage. Science 299:1309.

AACA. 2019. American Association of Clinical Anatomists. Job Openings. American Association of Clinical Anatomists, LaGrange, GA. URL: https:///clinicalanatomy.org/job_postings [accessed 26 February 2019].

AAMC. 2018. Association of American Medical Colleges. New research shows increasing physician shortages in both primary and specialty care. AAMC News. 11 April 2018. Association of American Medical Colleges, Washington, DC. URL: https://news.aamc.org/pressreleases/article/workforce_report_shortage_04112018/ [accessed 13 February 2019]. 
AAMC. 2019. Association of American Medical Colleges. U.S. Medical School Faculty, 2018. Association of American Medical Colleges, Washington, DC. URL:

https://www.aamc.org/data/facultyroster/reports/494946/usmsf18 [accessed 2 April 2019].

Ahmed K, Rowland S, Patel VM, Ashrafian H, Davies DC, Darzi A, Athanasiou T, Paraskeva PA. 2011. Specialist anatomy: Is the structure of teaching adequate? Surgeon 9:312-317.

Ahmed K, Rowland S, Patel V, Khan RS, Ashrafian H, Davies DC, Darzi A, Athanasiou T, Paraskeva PA. 2010. Is the structure of anatomy curriculum adequate for safe medical practice? Surgeon 8:318-324.

Alberts B, Kirschner MW, Tilghman S, Varmus H. 2014. Rescuing US biomedical research from its systemic flaws. Proc Natl Acad Sci U S A 111:5773-5777.

AOTA. 2019. American Occupational Therapy Association. OT Doctoral-Degree-Level Programs - Developing. The American Occupational Therapy Association, Inc., Bethesda, MD. URL: https://www.aota.org/Education-Careers/Find-School/Developing/OTD-Developing.aspx [accessed 13 February 2019].

ARC-PA. 2019. Accreditation Review Commission on Education for the Physician Assistant. Acredited Programs. Accreditation Review Commission on Education for the Physician 
Assistant, Johns Creek, GA. URL: http://www.arc-pa.org/accreditation/accredited-programs [accessed 13 February 2019].

ASHA. 2019. American Speech-Language-Hearing Association. Council on Academic Accreditation Program List. American Speech-Language-Hearing Association, Oshkosh, WI. URL:

https://www.asha.org/eweb/ashadynamicpage.aspx $?$ site $=$ ashacms $\& w e b c o d e=$ caalisting $\&$ caacat $=$ slp [accessed 13 February 2019].

Bader D, Dalley AF, Norden JJ, Nanney LB, Pettepher CC, Richmond AW, Wente S, Chalkley R. 2010. Development of a scientist-educator program. FASEB J 24:S827.827.

Bird MM. 1979. Scientists teaching gross anatomy. Med Educ 13:237-238.

Blevins CE, Cahill DR. 1973. Gross anatomy: Current courses, training programs, and prospective needs. J Med Educ 48:264-270.

Boston University. 2019. Ph.D. in Anatomy and Neurobiology (and Vesalius Module). Department of Anatomy and Neurobiology, Boston University, Boston, MA. URL: https://www.bumc.bu.edu/anatneuro/neuroscience-programs/anatomy-neurobiology-track [accessed 13 February 2019]. 
Brokaw JJ, O'Loughlin VD. 2015. Implementation of an education-focused PhD program in anatomy and cell biology at Indiana University: Lessons learned and future challenges. Anat Sci Educ 8:258-265.

CAPTE. 2019. Commission on Accreditation for Physical Therapy Education. Accredited PT \& PTA Programs Directory. American Physical Therapy Association, Alexandria, VA. URL: http://aptaapps.apta.org/accreditedschoolsdirectory/AllPrograms.aspx? UniqueKey= [accessed 13 February 2019].

Caruth GD, Caruth DL. 2013. Adjunct faculty: Who are these unsung heros of academe? Curr Issues Educ 16:1-9.

COCA. 2019. Commission on Osteopathic College Accreditation. Colleges of Osteopathic Medicine. February 2019 Ed. Chicago, IL: American Osteopathic Association. 7 p. URL: https://osteopathic.org/wp-content/uploads/2018/03/colleges-of-osteopathic-medicine.pdf [accessed 13 February 2019].

Dall T, West T, Chakrabarti R, Reynolds R, Iacobucci W. 2018. 2018 Update. The Complexities of Physician Supply and Demand: Projections from 2016 to 2030. Final Report. ${ }^{\text {st }}$ Ed. Washington DC: Association of American Medical Colleges. 54 p. URL: https://aamcblack.global.ssl.fastly.net/production/media/filer_public/85/d7/85d7b689-f417-4ef0-97fbecc129836829/aamc_2018_workforce_projections_update_april_11_2018.pdf [accessed 12 February 2019]. 
Drake RL, Lowrie DJ Jr, Prewitt CM. 2002. Survey of gross anatomy, microscopic anatomy, neuroscience, and embryology courses in medical school curricula in the United States. Anat Rec 269:118-122.

Drake RL, McBride JM, Lachman N, Pawlina W. 2009. Medical education in the anatomical sciences: the winds of change continue to blow. Anat Sci Educ 2:253-259.

Drake RL, Pawlina W. 2014. Multimodal education in anatomy: The perfect opportunity. Anat Sci Educ 7:1-2.

Drake RL, McBride JM, Pawlina W. 2014. An update on the status of anatomical sciences education in United States medical schools. Anat Sci Educ 7:321-325.

Eldred E, Eldred B. 1961. Supply and demand for faculty in anatomy. Acad Med 36:134-147.

Fraher JP, Evans DJ. 2009. Training tomorrow's anatomists today: A partnership approach. Anat Sci Educ 2:119-125.

Gogalniceanu P, Fitzgerald O’Connor E, Raftery A. 2009. Undergraduate anatomy teaching in the UK. Ann R Coll Surg Engl 91:102-106. 
GMC. 2019. General Medical Council. New schools and programmes currently under review. General Medical Council, London, UK. URL: https://www.gmc-uk.org/education/how-wequality-assure/medical-schools/new-schools-and-programmes-currently-under-review [accessed 9 January 2019].

Hall P, Keely E, Dojeiji S, Byszewski A, Marks M. 2004. Communication skills, cultural challenges and individual support: challenges of international medical graduates in a Canadian healthcare environment. Med Teach 26:120-125.

HigherEd Direct. 2019. Higher Education Publications. College Administrator Data/Turnover Rates: 2016-Present. Higher Education Publications, Inc., Reston, VA. URL: https://hepinc.com/newsroom/college-administrator-data-turnover-rates-2016-present [accessed 2 April 2019].

HigherEdJobs. 2019. HigherEdJobs, State College, PA. URL: http://www.higheredjobs.com [accessed 26 February 2019].

Kerby J, Shukur ZN, Shalhoub J. 2011. The relationships between learning outcomes and methods of teaching anatomy as perceived by medical students. Clin Anat 24:489-497.

Lachman N, Christensen KN, Pawlina W. 2013. Anatomy teaching assistants: Facilitating teaching skills for medical students through apprenticeship and mentoring. Med Teach 35:e919_e925. 
LCME. 2018. Liaison Committee on Medical Education. Accredited MD Programs in the United States. Liaison Committee on Medical Education, Washington, DC: URL: http://lcme.org/directory/accredited-u-s-programs [accessed 13 February 2019].

Lufler RS, Zumwalt AC, Romney CA, Hoagland TM. 2010. Incorporating radiology into medical gross anatomy: Does the use of cadaver CT scans improve students' academic performance in anatomy? Anat Sci Educ 3:56-63.

Malamed S, Seiden D. 1995. The future of gross anatomy teaching. Clin Anat 8:294-296.

Marsland MJ, Lazarus MD. 2018. Ask an anatomist: Identifying global trends, topics and themes of academic anatomists using twitter. Anat Sci Educ 11:270-281.

McBride JM, Drake RL. 2018. National survey on anatomical sciences in medical education. Anat Sci Educ 11:7-14.

McCuskey RS, Carmichael SW, Kirch DG. 2005. The importance of anatomy in health professions education and the shortage of qualified educators. Acad Med 80:349-351.

McDonnell L, Usherwood T. 2008. International medical graduates - Challenges faced in the Australian training program. Aust Fam Physician 37:481-484. 
Moosman DA. 1980. A surgeon's view: The decline and perhaps the fall of gross anatomy instruction. Am J. Surg 140:266-269.

Moxham BJ, Moxham SA. 2007. The relationship between attitudes, course aims and teaching methods for the teaching of gross anatomy in the medical curriculum. Eur J Anat 11:19-30.

Moxham BJ, Plaisant O. 2007. Perception of medical students towards the clinical relevance of anatomy. Clin Anat 20:560-564.

Mullan F, Politzer RM, Davis CH. 1995. Medical migration and the physician workforce. International medical graduates and American medicine. JAMA 273:1521-1527.

Older J. 2004. Anatomy: A must for teaching the next generation. Surgeon 2:79-90.

Orsbon CP, Kaiser RS, Ross CF. 2013. Physician opinions about an anatomy core curriculum: A case for medical imaging and vertical integration. Anat Sci Educ 7:251-261.

Patel KM, Moxham BJ. 2008. The relationships between learning outcomes and methods of teaching anatomy as perceived by professional anatomists. Clin Anat 21:182-189.

Pennsylvania State University. 2019. Anatomy PhD: Deeper Training in Anatomical Sciences. Penn State College of Medicine, Hershey, PA. URL: http://med.psu.edu/anatomy-phd [accessed 13 February 2019]. 
Plaisant O, Cabanis EA, Delmas, V. 2004. Going back to dissection in a medical curriculum: the paradigm of Necker-Enfants Malades. Surg Radiol Anat 26:504-511.

Plaisant O, Stephens S, Apaydin N, Courtois R, Lignier B, Loukas M, Moxham B. 2014. Medical students' attitudes towards science and gross anatomy, and the relationship to personality. J Anat 224:261-269.

Rhodes D, Fogg QA, Lazarus MD. 2018. Dissecting the role of sessional anatomy teachers: A systematic literature review. Anat Sci Educ 11:410-426.

Richardson-Hatcher A, MacPherson B, Gould D, Brueckner-Collins J. 2018. Assessing the impact of the graduate certificate in anatomical sciences instruction: A post-degree survey. Anat Sci Educ 11:516-524.

Rizzolo LJ, Drake RL. 2008. Anatomists debate the value of a teaching credential. Anat Sci Educ 1:60-67.

Santana S. 2003. Wanted: More anatomy instructors-institutions explore ways to cope with shortages. AAMC Rep 13:6-7. 
Schaefer AF, Wilson AB, Barger JB, Azim HM, Brokaw JJ, Brooks WS. 2019. What does a modern anatomist look like? Current trends in the training of anatomy educators. Anat Sci Educ (in press; doi:10.1002/ase.1806).

Speakman RJ, Hadden CS, Colvin MH, Cramb J, Jones KC, Jones TW, Kling CL, Lulewicz I, Napora KG, Reinberger KL, Ritchison BT, Rivera-Araya MJ, Smith AK, Thompson VD. 2018 a. Choosing a path to the ancient world in a modern market: The reality of faculty jobs in archeology. Am Antiquity 83:1-12.

Speakman RJ, Hadden CS, Colvin MH, Cramb J, Jones KC, Jones TW, Lulewicz I, Napora KG, Reinberger KL, Ritchison BT, Edwards AR, Thompson VD. 2018b. Market share and recent hiring trends in anthropology faculty positions. PLoS One 13:e0202528.

Stimpson JP, Li T, Shiyanbola OO, Jacobson JJ. 2014. Financial sustainability of academic health centers: Identifying challenges and strategic responses. Acad Med 89:853-857.

Sugand K, Abrahams P, Khurana A. 2010. The anatomy of anatomy: A review for its modernization. Anat Sci Educ 3:83-93.

Waterston SW, Stewart IJ. 2005. Survey of clinicians' attitudes to the anatomical teaching and knowledge of medical students. Clin Anat 18:380-384. 
Wilson AB, Barger JB, Perez P, Brooks WS. 2018. Is the supply of continuing education in the anatomical sciences keeping up with the demand? Results of a national survey. Anat Sci Educ $11: 225-235$.

Yammine K. 2014. The current status of anatomy knowledge: Where are we now? Where do we need to go and how do we get there? Teach Learn Med 26:184-188. 


\section{FIGURE LEGENDS}

\section{Figure 1: Primary responsibilities of anatomical sciences educators by discipline.}

Survey respondents categorized educators in cell biology and each of the four core anatomical science disciplines as either education- research- or patient/clinical care-focused faculty. Respondents were able to select all that apply.

Figure 2: Perceived recruitment difficulty by discipline: 2002 compared to 2018. 2018 survey respondents reported the anticipated difficulty in hiring qualified educators in cell biology and each of the four core anatomical science disciplines over the next 5 years (20192023). A four-point Likert scale was used (No Difficulty, Little Difficulty, Moderate Difficulty, Great Difficulty). 2002 survey respondents reported the anticipated difficulty expected over the next 5 years (2003-2007) in hiring qualified educators in gross anatomy, histology, and

neuroanatomy. A three-point Likert scale was used (Little Difficulty, Moderate Difficulty, Great Difficulty). Data from the 2002 survey are used with permission from R. McCuskey (McCuskey et al., 2005).

Figure 3: Current and projected number of job openings in the anatomical sciences. Responding department chairs and vice chairs (or equivalent) identified the current number of open, unfilled anatomical sciences educator faculty (academic staff) positions and reported the number of anticipated new positions over the next five years (2019-2023). Data were grouped geographically. 
Figure 4: Candidate qualities/experiences and degrees/disciplines preferred by leaders in anatomy-related departments.

Survey respondents prioritized candidates' qualities and experiences (A) and ranked preferred degrees/disciplines (B) in the context of a job applicant seeking a full-time faculty (academic staff) position as an anatomical sciences educator using a 5-point Likert scale (Not a priority, Low priority, Neutral, Moderate priority, High priority).

\section{TABLE HEADERS}

Table 1: Fill time of and number of qualified applicants applying to anatomy educator job postings on the American Association of Anatomists' job board between 2017 and 2018 as reported by departmental leaders.

Table 2: Demographics of full-time anatomy educator job postings for openings at U.S. medical institutions between 2017 and 2018.

Table 3: Number of U.S. medical and health professions programs established between 2014 and 2018 according to publically available accrediting agency records. 